\title{
Orientación y lugar en la escritura de Rosalía de Castro. La función del lugar americano ${ }^{1}$
}

\author{
FERNANDO CABO ASEGUINOLAZA
}

\begin{abstract}
Orientation and Locus in the Narrative Writing of Rosalia de Castro. The Function of American Referentiality. This article explores the relationship between the narrative work of Rosalía de Castro, a woman writer customarily identified with the emergence of modern Galician literature, and the American space. This area acquired an undeniable significance from the point of view of the diffusion of the poetry of Rosalía, but perhaps the importance of repeated American presences of very different character throughout her work in prose has not been appreciated in the same way. Imaginary geographies, and characters such as migrants, returnees, the public man, the criolla or the Yankee help to identify a less self-absorbed narrative world than has often been considered. But, on the other hand, the transatlantic referentiality hinted to by Castro is far from non problematical. It reveals a number of spatial tensions, which contribute to the appreciation of a controversial and complex work.
\end{abstract}

Keywords: Rosalía de Castro, Galician literature, America, spacial imagery

DOI: http://dx.doi.org/10.12697/IL.2013.18.1.14

Siendo Rosalía de Castro una escritora situada entre dos lenguas, con una vinculación no poco conflictiva con sistemas o protosistemas literarios diferentes - el gallego y el castellano, pero también, de manera muy viva, el de la literatura europea e internacional del momento - y con una actitud muy poco complaciente respecto a los presupuestos que parecían destinados a encauzar su escritura, no puede sorprender la importancia crucial que en la interpretación de su obra adquieren los espacios de la representación y, en otro nivel, los de la circulación y proyección editorial de sus obras. Desde el punto de vista de las estrategias de representación son espacios diversos, plurifacéticos y, no obstante el peso que Galicia tiene como referente fundamental, con un nivel de redundancia muy

1 Este artículo se inscribe en el proyecto de investigación "La producción del lugar. Cartografías literarias y modelos críticos” (FFI2010-15699), financiado por el Ministerio de Ciencia e Innovación del Gobierno de España. 
Orientación y lugar en la escritura de Rosalía de Castro. La función del lugar americano

escaso, sobre todo en lo que se refiere a su prosa. Y por lo que toca a la dimensión editorial, con todo lo que implica en cuanto al acceso a la esfera pública de una escritora entre 1857 y 1885 , sobresale la tensión entre la publicación en un ámbito gallego y otro madrileño, aunque no deba atribuirse a un mero ejercicio de voluntad o estrategia, así como la importancia de la proyección americana, de plena relevancia para garantizar el acceso a una condición autorial pública, de una parte nada desdeñable de su obra.

Sobre todo para los espacios de la representación, no habría que sustraer el discurso literario rosaliano de las demarcaciones espaciales que se hicieron tan relevantes en la estética literaria decimonónica. La oposición entre lo septentrional y lo meridional, las trazas de un orientalismo muy visible, la emergencia de un imaginario oceánico, con claros precedentes en Scott y Byron; o la sugerencia de una articulación territorial que transparenta algunos de los ejes de la espacialización estatal de la España decimonónica son algunas de las manifestaciones más perceptibles de esa presencia. Chenxi Tang (2008) ha mostrado la manera en que a principios del siglo XIX dio en aflorar una nueva subjetividad geográfica, que a su vez trajo consigo una concepción de la cultura intrínsecamente espacializada. Ahí está, en otro nivel y por lo que toca a Galicia, el énfasis geográfico que imprimió desde muy pronto Manuel Murguía al discurso regionalista. Hay, en este sentido, razones para proponer la obra rosaliana como una manifestación singular de esa subjetividad. La problematización del cosmopolitismo, así como de la pura identidad local, que son aspectos sustanciales de la escritura rosaliana, se articulan en un marco donde la espacialidad y la gramática de los lugares se vuelve decisiva.

El hecho, que subraya Tang, de que la nueva geografía que emerge en torno a 1800 hiciese de nociones como las de paisaje o región elementos decisivos para la articulación de un conocimiento general sobre la tierra no es ajeno a la literatura del momento, en que se inscribe de modo pleno la obra de Rosalía. Uno de los aspectos claves de esta nueva percepción es la figuración de lo que Chenxi Tang caracterizaba, con una no reconocida deuda fenomenológica, como un "oriented space": "orientation consists in the subjective feeling of bodily oneness with space” (2008: 11). Si se recorre la narrativa rosaliana desde esta perspectiva no será difícil reconocer en las aporías de la orientación - de la identificación con el lugar - una de las líneas recurrentes de una escritura ciertamente compleja, en la que tanto pesan los procedimientos de la producción del lugar.

El lugar, eso sí, entendido como un complejo de dimensiones diferentes que afectan al núcleo semántico de un texto. Un lugar que en buena medida se produce desde el texto y que desmiente el entendimiento consagrado de la localidad de Rosalía como limitada a una mera identificación con la tierra o a una posición resistente frente a Castilla. Quizá fuese bueno, antes de ir más 
allá, recordar la importancia que de entrada tienen en términos generales las demarcaciones espaciales en la narrativa decimonónica, lo que sin duda puede leerse en la clave planteada por Benedict Anderson al entender la novela como representación de la nación y como una de las bases de su consistencia imaginaria. Pueden ilustrarlo entre otras menciones posibles la estratificación espacial articulada por Balzac, autor muy presente en la autora gallega, en ese extraordinario complejo textual que es la Comédie Humaine, donde clasificaba los relatos entre Scènes de la vie de Paris, Scènes de la vie de province y Scènes de la vie de campagne, además de otros ámbitos no menos innovadores como, por ejemplo, las Scènes de la vie privée. A este respecto tienen también una especial pertinencia los “Apuntes autobiográficos" que, a poco de su intervención en el homenaje a Rosalía, abrían la primera edición de Los pazos de Ulloa (1886) de Emilia Pardo Bazán. En ellos presentaba una sugerente visión de la relación entre la novela y el espacio nacional mediante una especie de repartición de los ámbitos locales y regionales, por la imposición del medio ambiente, entre los escritores más destacados de la sociedad literaria (Cabo 2012: 475-487).

Rosalía no plantea de forma explícita un diseño programático parangonable a los de Balzac o Pardo Bazán. Sin duda su perspectiva era otra. Recordemos, en todo caso, las localizaciones de sus novelas. La hija del mar (1859) se desarrolla en un paraje apartado de la costa atlántica gallega. Flavio (1861) transcurre parcialmente en una ciudad que es trasunto de Santiago - presentada como escenario un tanto sorprendente del spleen del protagonista y de la presión de la muchedumbre (Rábade 2011) - y en varios entornos situados en un ámbito rural no demasiado alejado. Ruinas (1866) tiene por escenario una villa, claramente diferenciada de la capital provincial y de Santiago como sede universitaria, identificable sin apenas dificultad con Padrón. Su siguiente novela, la más conocida, El caballero de las botas azules (1867) está emplazada de manera muy notoria en la Corte, en los meses previos a la revolución de 1868. Y por último - si dejamos a un lado las piezas prosísticas más breves -, El primer loco (1881) vuelve a Santiago, y, en lo fundamental, al emplazamiento del vecino monasterio de Conxo cuando su posible transformación en manicomio era el motivo de una notable polémica pública. Es apreciable la diversidad, incluso axiológica, de los espacios novelísticos, aunque siempre en una escala que no es, al menos de forma patente, la de la ordenación jerárquica de los espacios del nuevo estado liberal en formación. También que la aproximación rosaliana no es en absoluto costumbrista. Destaca, incluso de forma sorprendente, la dimensión abstracta de muchas de estas representaciones, a menudo también fragmentarias, con muy escasa servidumbre a los detalles o al pintoresquismo. Están cruzadas, en otras palabras, por un principio alegórico, que se hace especialmente patente en El caballero de las botas azules y El primer loco. 
De lo visto hasta ahora pueden deducirse algunas de las tensiones básicas en el caso de Rosalía. Una es la búsqueda de un público, en la que el desencuentro con los lectores del entorno social y geocultural más próximo es evidente. Distintos episodios lo ilustran de manera inequívoca (prólogos, cartas, textos como "Las literatas", donde se plasma la presión casi física de la opinión circundante...). Cuenta aquí, por supuesto, su ostensible posición pública como mujer escritora, muchas veces ligada a la "ansiedad de la autoría” a que se refirieron Sandra M. Gilbert y Susan Gubar (1979), y en la adopción de figuras enunciativas inequívocamente femeninas. También, por cierto, las tensiones entre la periferia y la capitalidad literaria menor, que era entonces Madrid, junto con el horizonte muy vivo para nuestra autora de la gran literatura internacional, sobre todo europea, del momento. Son tensiones que manifiestan algunos conflictos básicos en la constitución del moderno sistema literario español en el convulso período que conduce desde los últimos años de la monarquía isabelina a la Restauración borbónica.

Nada de ello es óbice para reconocer un denodado y constante esfuerzo por hacerse con una posición en Madrid, desde el primer momento. Madrid fue el lugar de publicación de la mayoría de sus obras (La flor, Imp. M. González, 1857; Follas Novas, Aurelio J. Alaria, 1880; En las orillas del Sar, Ricardo Fe, 1884; Flavio, La Crónica de Ambos Mundos en 1861; Ruinas, El Museo Universal, 1866; El primer loco, Moya y Plaza, 1881). En Galicia se publicaron La hija del mar, Cantares gallegos, A mi madre (en 1859 la primera y en 1863 la dos últimas, todas en la imprenta viguesa de Juan Compañel, viejo amigo de Murguía) y El caballero de las botas azules (Soto y Freire, Lugo, 1867).

Antonio Odriozola (1986) sugería varias opciones de ordenación de las ediciones rosalianas, que puede inducir a algunos equívocos. En primer lugar, trataba conjuntamente las publicaciones de Murguía y Rosalía mostrando una pauta común en ambos, en lo que puede entenderse como una indicación del papel mediador del marido sobre la esposa en su acceso al mundo editorial. Razones legales, que tienen que ver con la representación y responsabilidad que la ley reservaba al cabeza de familia (Davies 1987), y motivos que atañen a la articulación del acceso a la esfera pública, en la que las relaciones con el mundo editorial y político trenzadas por Murguía desde su época de estudiante resultan decisivas, explican esa perspectiva, aunque sin duda han contribuido a ocultar la especificidad de las posiciones de la propia Rosalía. Apuntaba Odriozola, por otro lado, a la existencia de tres etapas en la trayectoria editorial del matrimonio: una madrileña, otra gallega y de nuevo una final madrileña. Pero ha de notarse que la secuenciación cronológica de esas tres etapas, en las que inciden de modo poderoso los vaivenes de la situación política en el marco estatal y sus consecuencias sobre la situación del matrimonio, no 
resulta siempre nítida y, sobre todo, que el lugar de publicación no es lo único que ha de tomarse en cuenta a la hora de sacar conclusiones. Por ejemplo, el editor y difusor no coincide de manera necesaria con el impresor. La hija del mar la imprimió Juan Compañel en Vigo, pero el editor fue la célebre Librería de Bailly y Ballière en Madrid. Cantares gallegos (Vigo, 1863), que tuvo uno de sus mercados entre los emigrantes habaneros, conocerá, por otra parte, una segunda edición madrileña, ampliada, en 1872 (Leocadio López). Puede sorprender a este respecto el caso de El caballero de las botas azules, que se publicó en Lugo, aun siendo la única novela rosaliana localizada en la Corte. Sólo cabe entenderlo como un indicio de las dificultades políticas y personales de acceso al ámbito editorial madrileño en algunos momentos y de las tensiones de su situación periférica. Pero aún más significativo es que Follas novas se imprimiese en Madrid y que su edición corriese a cargo de La Propaganda Literaria de La Habana, ligada íntimamente a los círculos de la emigración gallega y cuyo director era Alejandro Chao. La princeps de Follas novas constituye de hecho un caso verdaderamente singular desde el punto de vista del carácter orientado del acceso y la proyección de la obra rosaliana. No sólo la editora de esta publicación madrileña es una institución habanera vinculada a la emigración gallega, sino que la dedicatoria de Rosalía, fechada en Santiago, se dirige a los miembros de la Sociedad de Beneficencia de los Naturales de Galicia en La Habana. Además, y desde un punto de vista lingüístico, ha de considerarse que la portada y la cubierta utilizan el castellano, lo mismo, a diferencia de la dedicatoria y el prefacio ("Dúas palabras d'a autora”) de la escritora, que el extenso prólogo de Emilio Castelar. Paratextos y peritextos conforman un testimonio de las complejidades de la orientación pública, nada obvia, de la escritura rosaliana en un marco sistémico e institucional mucho más complejo de lo que se acostumbra a aceptar. Lo mismo que en la portada de Follas novas, a pesar de la diferencia lingüística, al final de En la orillas del Sar se indicaba que sus ejemplares se vendían en los locales madrileños de La Ilustración Gallega y Asturiana y también en la sede habanera de La Propaganda Literaria. De hecho, como es sabido, una parte muy significativa del libro, con variantes a veces relevantes, habían aparecido en las páginas del diario de Buenos Aires La nación Española entre 1882 y 1883.

Apunta así una primera dimensión transatlántica, que hace patente la necesidad de una nueva cartografía que acoja la complejidad - que no contradice su extrema precariedad - de las redes de producción y recepción literarias en la literatura gallega del XIX (Hooper 2006). Un aspecto que, por cierto, ya había destacado Pardo Bazán en su discurso de 1885. Entre otras cosas, esta dimensión manifiesta una vinculación intensa a lo que hemos llamado producción del lugar. En este caso, nos situamos ante un ámbito trasatlántico que hace 
Orientación y lugar en la escritura de Rosalía de Castro. La función del lugar americano

posible el acceso a la esfera pública de una parte más que relevante, aunque parcial, de la obra de Rosalía, y que no sólo afecta a la percepción, digámoslo así, integrista u orgánica de los orígenes de la literatura gallega contemporánea, sino también a la manera de entender ciertas fallas en la conformación de la literatura española decimonónica. Dejando aparte por un momento las representaciones poéticas de la emigración en la obra de Castro, fundamentalmente desde la perspectiva del que se va y de los que se quedan o, si acaso, del que regresa (nunca del que llega ni de la sociedad que recibe al que llega), viene bien recordar una pertinente observación de Catherine Davies (2005: 173). Que después de la segunda edición de Cantares gallegos, la madrileña de 1872, los emigrantes gallegos de Argentina y, muy especialmente, de Cuba se convertirían en el público fundamental de su obra. Hasta el punto de que, según Davies (2005: 176), "Castro necesitaba que los hombres de la diáspora gallega leyeran y publicaran sus poesías; se podría decir que se dirigía a ellos precisamente”.

La sugerencia viene a añadir una nueva dislocación a la posición tan compleja de Rosalía en la esfera pública, tanto gallega como española. Quizá por ello, según señala de nuevo Davies, la ceguera o el silencio de Rosalía respecto a fenómenos como la lucha por la independencia cubana o la denuncia de la esclavitud, que eran cuestiones públicas en España desde la década de los 70. Piénsese en que 1880 no sólo es el año de Follas novas, sino también, por ejemplo, el de la segunda deportación de José Martí de la isla caribeña tras la conocida como Guerra Chiquita. Y lo que, en cierto modo, es un corolario de lo anterior: la intrascendencia, en lo que se refiere a Cuba, de su obra más allá de los círculos de la Galicia emigrante. Martí, por ejemplo, no acusó recibo de la obra de Rosalía en su artículo "Modern Spanish Poets" de noviembre de 1880, aparecido originalmente en inglés en las páginas del diario neoyorquino The Sun, aunque recordaría más adelante con aprecio un pasaje del prefacio de Follas novas en una carta particular fechada en enero de 1891 (Alonso Montero 2004: 73-74). Al margen de las matizaciones posibles al eco de la poesía rosaliana entre los literatos cubanos, se suma a lo anterior el hecho de que Cuba, por su condición de destino de la emigración peninsular, en el contexto de una situación colonial que condiciona en muy distintos niveles la configuración del espacio público español, tuviese una connotación sobre todo negativa y de carácter subalterno para la autora de Follas novas.

Pero más allá de estas cuestiones, las referencias americanas recorren toda su obra y acaso sea un tanto precipitado considerarlas marginales o meramente anecdóticas. Esto es así no sólo en la obra en verso, donde la emigración a América es uno de los ejes temáticos centrales. También, aunque de manera menos ostensible, en la obra narrativa. Un caso singular, por supuesto, lo tenemos en una pieza breve como "El cadiceño” (Almanaque de Galicia, Soto y Freire, Lugo, 
1865), con su representación caricaturesca y profundamente crítica - la retratista, que se introduce en la propia representación, expone de manera explícita el resultado a partir de la dialéctica retrato / caricatura -, sobre la base de una mímesis lingüística derogatoria, de dos emigrantes retornados, uno de Cádiz y otro de La Habana, lugares que se presentan casi como un continuum indiferenciado. El telón de fondo no es otro que el proceso de aculturación ligado a la emigración económica (López Sández 2012). Hay otras muchas presencias americanas. En El caballero de las botas azules, publicado en el mismo lugar y sólo dos años después que "El cadiceño", comparece, con trazos no poco caricaturescos, el personaje de Marcelina la Blonda - es decir, la rubia (la fórmula "blonda cabellera" es empleada por Gertrudis Gómez de Avellaneda en varias ocasiones, y también, entre otros, por Zorrilla o Castelar) -, explícitamente presentada como criolla - de la que se resaltan los "ojos azules"- y poetisa, implicando una imagen de Cuba básicamente disociada e incluso antagónica de la del cuadro que presentaba en "El cadiceño" y de los espacios de la emigración que serán frecuentes en otras obras. En este caso, se trata de la mujer natural de Cuba, de la clase dominante y prestigiosa en la isla, que llega a la Corte sin abdicar de su identidad americana y 'extranjera':

se paseaba lentamente cogida al brazo de Marcelina la blonda, formando ambas un contraste encantador; pues mientras la primera murmuraba con desmayado esfuerzo palabras misteriosas, eco imperfecto de sus sentimientos sublimes, la segunda, viva como el pensamiento y despreocupada como todo el que pisa suelo extranjero (era criolla), no hacía más que hablar en voz muy alta de su adorada América cual pudiera hablar del mismo cielo con sus potestades, ángeles, arcángeles y serafines - que eran ellas, las criollas -, y de las poetisas cubanas, en cuyo número tenía el alto honor de contarse. Dote que le había sido transmitida por sus ascendientes desde la quinta generación, por ser ésta allí costumbre muy añeja y usada con tan suma facilidad que, de serlo tanto, parece ya cosa de poco valer. (Castro 1944: 627-628)

Junto a esta, otras referencias en general muy distanciadas y desdeñosas que apuntan genéricamente a América o el Nuevo Mundo, salvo cuando es la propia Marcelina quien las hace (Castro 1944: 630, 632...).

América, y particularmente Cuba, asumen en el imaginario rosaliano, de acuerdo con estereotipos más generales, una valencia particular con respecto a la ansiedad producida por la inflación literaria y la plebeyización del gusto que deja expresa nuestra autora en distintos pasos de su obra. La alusión a las "poetisas cubanas" puede conectarse con el pretencioso barbero, presentando 
Orientación y lugar en la escritura de Rosalía de Castro. La función del lugar americano

en clave de sátira, que en "Las literatas", una carta ficticia sobre las condiciones de la escritura femenina, explica su retraso a la cita para afeitar al marido de la escritora por haber estado ocupado acabando una novela y tratando con su editor. Lo significativo es que tales veleidades se vinculen a su experiencia habanera - como emigrante o, acaso, como soldado - y lleven a la autora que firma la carta a romper todos sus escritos por pura irritación y "orgullo literario". No deja de ser relevante, en efecto, que estas tensiones y reticencias relativas a la democratización de la institución literaria (de que ha tratado con mucha pertinencia Jacques Rancière) se muestren de manera tan palpable en una escritora tantas veces asociada a una posición demótica y que además, en el caso presente, con una referencia geográfica y espacial tan precisa como es la cubana.

Por cierto que en el marco de las referencias cubanas de El caballero de las botas azules, se alude incluso, aunque al paso, al cable submarino para uso telegráfico que unió América del Norte y Europa en 1866, tras reiterados intentos, o, quizá, al que conectaría La Habana y Cayo Hueso en 1867 - esto es, el mismo año que la novela - (Castro 1944: 645; Díaz Martín 2000: 527). Se intuye así un imaginario transatlántico en el que Estados Unidos empezaba a tener un papel importante, especialmente en relación con Cuba. Por otra parte, el protagonista, al que antes de su transformación se presentaba en el sorprendente preliminar "Un hombre y una musa", se caracteriza por su experiencia americana en lugares como las Antillas o, más ampliamente, el Nuevo Mundo, del que se mencionan los "ríos de oro"... La obra de Rosalía se inscribe también, pues, en el espacio colonial, con todas sus ambigüedades, y en un discurso subyacente en el que la presencia de América, casi espectral en la medida en que no es nunca objeto de una representación directa (Loureiro 2003), se hace manifiesta no sólo como destino de la emigración. Y en donde las figuras del criollo y la del emigrante retornado comparten, a pesar de ser casi la inversión especular el uno del otro, una identidad híbrida, en cierto modo perturbadora, que parece ser considerada con un recelo a veces evidente, entre otras cosas por sus implicaciones socioeconómicas y comunitarias (véase también Rábade 2012: 89). Al mismo tiempo, en las alusiones directas a América abunda lo estereotipado - un mundo que no es objeto de experiencia -: vírgenes bosques, extensas pampas... Incluso en Ruinas, aparentemente ajena a cualquier referencia americana, el único giro relevante en la acción, que tiene que ver con la herencia recibida por don Braulio, remite a Ultramar: el dinero procede de un sobrino muerto allá, y la noticia le llega al comerciante arruinado, por su rechazo de la lógica económica burguesa, a través - como ha notado Francisco Rodríguez (2011: 207) - de un "caiceño" (536). Se viene a la mente, salvadas las distancias, la lectura de Mansfield Park incluida por Edward Said en Culture and Imperialism (1994), donde la propiedad antillana de sir Thomas Bertram, tampoco 
representada nunca en modo directo, se convertía en la condición necesaria para el sostenimiento económico y social del recoleto lugar de la ficción de Jane Austen, visto así como un integrante más de una estructura imperial de largo alcance. Y en El primer loco irrumpía la figura - como los emigrantes retornados de "El cadiceño" también objeto de una mímesis lingüística degradante de un americano de un linaje distinto a todos los demás, el yanqui, que se casa con la amada del protagonista, provocando su definitiva caída en la locura.

Hay, pues, un americanismo plurifacético en la obra de Rosalía, ligado a un espectro de figuras muy diferentes: los emigrantes, los retornados, el hombre público, las criollas, el yanqui... Además, por supuesto, de la proyección trasatlántica de su obra y del propio estatuto público de su figura autorial. Pero hay unos antecedentes que implican otra visión de lo americano, no del todo extinta en obras posteriores, que nos conduce hacia algunos aspectos sorprendentes y clarificadores de la complejidad de la posición geocultural de la obra de Rosalía. Así, por cierto, el potente imaginario atlántico que se hace aparente en La hija del mar, primera de sus novelas. Algunas de sus peculiaridades afectan a su presentación de un territorio, volcado sobre el océano, donde priman la apertura de las fronteras marítimas, frente a una presencia del interior sólo indirecta y fundada en un principio negativo de representación (Cabo 2011, García Candeira 2012), las alusiones al comercio esclavista y podría decirse que también una notable trascendencia literaria que se manifiesta de distintas maneras. Atiéndase a que uno de los lugares cruciales en la narración es la casona aislada de Alberto Ansot, en el entorno desolado de la costa de Muxía, cuyo final es un dramático incendio que se ha vinculado de forma plausible con el que destruyó Thornfield (Barro 1972), la mansión donde transcurre buena parte de la acción en Jane Eyre (1847), y que también sugería un trasfondo antillano de la novela de Charlotte Bronte, especialmente centrado en la figura de Bertha, esa "madwoman in the attic" que dio título al célebre libro de Sandra Gilbert and Susan Gubar. Rosalía conecta con un imaginario atlántico de naturaleza literaria y trasfondo colonial inscrito en la tradición literaria de la primera mitad del XIX (Cabo 2011).

Otro de los precedentes significativos lo encontramos en una novela de Nicomedes Pastor Díaz publicada en libro el año anterior a La hija del mar, en 1858 por tanto: De Villahermosa a la China, título que revela ya la amplitud de un imaginario espacial en el que se encuadra, con un énfasis notable, el Valle de las Flores, transposición literaria del Viveiro natal del autor. No parece improbable que algunos de los elementos descriptivos de esta novela hayan dejado una huella en la de Rosalía: Díaz fue autor muy valorado por Murguía y al que acudió en alguna ocasión en busca de apoyo por la influencia de Díaz en los círculos de gobierno. Sin embargo, lo más llamativo son las diferencias en la 
Orientación y lugar en la escritura de Rosalía de Castro. La función del lugar americano

presentación de estos lugares de la Galicia costera, plasmados en ambos casos como decididamente septentrionales, en el marco del paradigma tan asentado de la oposición entre norte y sur. En Nicomedes Pastor Díaz, la contraposición al "Mediodía de España”, que, "casi el Oriente, casi los trópicos” (Díaz 1972: 56), funciona como un eje geoliterario relevante (y los trópicos, por cierto, son una de las representaciones culturales de lo americano más reiterativas en este momento). El caso es que el lugar del viveirense aparece como contraposición pastoral a la capital - noción clave en estos años -, de una manera bien explícita, y como objeto de una localización topográfica que la sitúa en "uno de los radios más extensos de la Península” (Díaz 1972: 85), en relación, claro, con la fijación de la centralidad capitalina. Nicomedes Pastor Díaz, al fin, se había iniciado en la vida política como colaborador de Javier de Burgos, uno de los grandes responsables de la estructura del estado liberal y, en concreto, de su conformación provincial. Los lectores aludidos en De Villahermosa a la China son, en todo caso, patentemente capitalinos, capaces de reconocer los salones del madrileño Palacio de Villahermosa. Lo que no quita para que la capital sea vista, nada excepcionalmente (Mainer 2003), como precaria y deficiente, hasta el punto de negársele el privilegio de la representación directa: "No la describiremos: las descripciones de Madrid no son poéticas. Faltan la inmensidad, y el misterio, y la larga distancia, y la antigüedad y la magnificencia a nuestra capital, que ni nombre de ciudad admite" (Díaz 1972: 46).

Por el contrario, el espacio costero de la novela de Rosalía no entraña ninguna referencia a la capital, al menos de una manera diáfana. Hay, eso sí, una alusión por parte de la narradora a un ámbito contrapuesto al contorno costero de Muxía, que implica una distancia social y al menos también lingüística, aunque sea este último un factor que queda significativamente rebajado en la estrategia de representación rosaliana. Es la alusión a "nuestros salones", en los que la narradora sitúa a sus lectores aludidos, y que, como en el caso de la novela de Nicomedes Pastor Díaz, muy bien pudieran estar emplazados en Madrid: "Teresa gozaba de aquella naturaleza excepcional como pudiéramos hacerlo nosotros entre el ruido de una fiesta. Muy lejos está seguramente de parecerse la música de nuestros salones al silbo agudo del viento que, rodando sobre el techo de su cabaña solitaria, le acompañaba en su rezo fervoroso y en su sueño inquieto y desasosegado la mayor parte de sus noches de soledad" (Castro 1944: 29). Con una inversión de la perspectiva, se leía en De Villahermosa a la China: "los ecos del murmullo de la sociedad llegan apenas a los confines de la región donde se esconde su retiro” (83). Sin embargo, el entorno social de salones y fiestas en el que parece situarse al ámbito de la enunciación de $L a$ hija del mar no se traslada de modo abierto a los ejes constitutivos del mundo ficcional, donde Madrid o la capital no tienen presencia explícita. No la tiene 
en general, como se ha dicho, el interior situado más allá de espacio liminal y permeable de la costa, que se proyecta fundamentalmente a través del mar por el que llegan y marchan los personajes. La acción progresa, en suma, a través de las fronteras marítimas. Algo parecido también a lo que sucede en De Villahermosa a la China.

En la apertura oceánica de la novela de Rosalía, no obstante, América tiene una relevancia que está ausente en Díaz. Se trata de una relevancia que parece de tono muy distinto a la que hemos anticipado en otros sectores y momentos de la escritura rosaliana. Por una parte, se hace presente a través de lo que podríamos llamar un repertorio de imágenes y estereotipos que puntean el discurso narrativo, en relación muy estrecha con la panoplia realmente intensa de alusiones orientalistas (abundantes también en El caballero de las botas azules, por ejemplo). Componen un conjunto muy trabado de referencias a lo que Edward Said llamó una imaginative geography, cuyo carácter fundamentalmente abstracto, inducido por una dramatización de la distancia y la diferencia, marca no sólo el lugar americano ausente, sino también la representación aparentemente más inmediata de la geografía gallega de la hoy conocida como Costa da Morte, presentado por Rosalía como "este olvidado rincón de Europa”.

Habría mucho que decir de las afinidades entre americanismo y orientalismo a partir del XVIII, y sobre todo en la imaginación romántica. La escena europea conoció la proliferación de obras de tema incaico y, en general, americano (Macchi 2012), en la misma medida en que se incrementó la atracción del continente para las principales potencias. También se hicieron populares relatos o epopeyas que contribuyeron poderosamente a este imaginario, como Camiré de Florian, Atala de Chateaubriand, o Madoc de Southey. O en el terreno de la historiografía literaria, discursos en los que se hacía determinante el sublime natural, como el de Ferdinand Denis a propósito de la literatura brasileña. Pero también, algo más tarde, ha de contarse con la difusión de cierta lírica americanista en la Península. Por poner un caso, composiciones como Tropicales del limeño Manuel Nicolás Corpancho, que parecen evocar las Orientales de Victor Hugo, y que se publicaron en un periódico de tanta importancia para estas cuestiones como el madrileño La América. Crónica HispanoAmericana en agosto de 1858. En esas misma páginas apareció, por cierto, un extenso artículo inaugural de Emilio Castelar (buen amigo de Murguía), titulado sencilla y rotundamente "América”. Lo hizo en el primer número de esta cabecera en marzo de 1857, y en él despliega el tribuno las líneas fundamentales de un discurso americanista liberal donde la naturaleza y la poesía eran ejes dominantes. El artículo podría tomarse como exponente de la tesis de, por ejemplo, Alda Blanco (2012: 14), según la cual la forja de la España contemporánea habría dependido, a pesar de su fracaso y condición subalterna en un 
Orientación y lugar en la escritura de Rosalía de Castro. La función del lugar americano

contexto internacional, del "proyecto liberal de construir la nación moderna... inextricablemente ligado a una idea de imperio". Se trata, en suma, de algunos elementos de un discurso heterogéneo que estructura la retórica analógica de ciertos momentos de la novela de Rosalía, basada de manera característica en las referencias a una naturaleza sublime (Castro 1944: 58, 88...).

Pero América tiene también una función en la trama sobre la que conviene detenerse, porque es allá donde se sitúa la procedencia de Candora, madre de Esperanza tras su seducción por el traficante Ansot, junto a quien dejará el lugar americano ("un aislado y desconocido pueblo de América") para recalar en un pequeño puerto próximo a Muxía, a su vez un "olvidado rincón de Europa”. El contraste no puede ser más agudo:

y Candora vio bien pronto cambiarse el hermoso cielo de su patria por el nubloso y triste de uno de los pueblos cercanos a Mugía, lugar árido, salvaje, inculto, país de nieblas, en fin, que hacía recordar a la hermosa hija de los trópicos la pujante y viva vegetación de su patria, sus tibias auras cargadas de aroma, el brillante sol, el cielo transparente y la mar tranquila de aquellas costas en donde había nacido. El ruido eterno de una mar siempre irritada, y el agudo chillido de las aves marinas, era lo único que turbaba el largo silencio de tan triste soledad, soledad que le fue insoportable tan pronto como Alberto abandonó aquellos lugares dejándola sola, con la única esperanza de una pronta vuelta. (Castro 1944: 189-190)

Candora es, pues, una "hija de los trópicos". Y sus rasgos físicos esenciales son, como en el caso de Esperanza, los ojos azules, la piel blanca y los cabellos rubios. Los mismos, en suma, que los de la cubana Marcelina la Blonda de El caballero de las botas azules. Lo que es tanto como decir que la heroína de La hija del mar, ella y su madre, es una criolla, cuya semiótica racial contrasta de manera acusada no sólo con otros habitantes de América, absolutamente ausentes del horizonte rosaliano (al contrario de lo que ocurre en Camiré o Atala o Madoc), sino con los naturales de la costa gallega, definidos en términos generales por la negrura de cabellos y ojos. El énfasis sobre lo rubio llega al delirio en la Candora de la última parte de la novela:

Esas cabezas así - decía ella en voz baja y como hablando consigo misma -, esas cabezas rubias y pálidas las cortaría todas y haría con ellas un altar ante el cual me prosternaría, ¡son tan bellas! Pero como ésa [la de Esperanza, su hija] no he visto ninguna - añadió con exaltación y, levantándose rápidamente, se acercó 
a la enferma y le dijo con extraño acento -: ¿Quieres darme tu cabeza? ¡Yo la llevaré conmigo, yo la cubriré de flores! (Castro 1944: 185)

La apariencia física es la marca de la diferencia subjetiva, de la extrañeza radical con el medio (Ansot también se caracteriza por los ojos azules). Pero conviene alguna conclusión provisional sobre el lugar americano en una autora en la que la dimensión trasatlántica es tan importante. En La hija del mar, desde el punto de vista narrativo América aparece, en consonancia con su posición subalterna, mediante un relato metadiegético completivo (en boca de Ángela, antigua criada) - esto es, al margen del discurso narrativo dominante - y sugiere un pasado ominoso, una genealogía oculta y una violencia subterránea, pero de índole familiar y personal, fundamentalmente subjetiva por tanto. Lejos en principio de la América de los emigrantes, que marchan o regresan, o de la de la cubana Marcelina o, por supuesto, de la patria del yanqui de El primer loco, presentado según las pautas del discurso sobre la potencia norteamericana que comenzaba a hacerse omnipresente en Hispanoamérica y España por entonces. Sobre esta novela, aventuraba Ramón Otero Pedrayo (1969: 313) que "Berenice, nombre estelar, lejano, al entregarse al brutal yanqui pudiera simbolizar la alianza fatal de la razón y la materia”. Pero en todos los casos - sea a propósito de emigrantes, criollas o yanquis...- es una lugar al margen de la representación directa, un lugar vacío, disponible para acoger significados muy diversos, como contrapunto implícito a menudo del imaginario espacial de estado liberal en ciernes. En algunos casos, estos significados son herederos de marcos discursivos muy genéricos sobre lo americano de alcance europeo, en otros como un discurso mucho más específico y reactivo a partir de la sangría de la emigración, mas siempre con el trasfondo de la comprometida proyección imperial y colonial de española. Y quizá por ello puede decirse que conforma el principal lugar tercero en las representaciones espaciales de la literatura rosaliana, que irrumpe, transformándose, a lo largo de toda ella. A partir de ahí se abren cuestiones de indudable alcance al respecto de la configuración de un horizonte literario y de sus conexiones con un marco cultural, fundamentalmente moderno e internacional, que invita a indagaciones mucho más detenidas que las que aquí se apuntan. 
Orientación y lugar en la escritura de Rosalía de Castro. La función del lugar americano

\section{Fernando Cabo Aseguinolaza}

Departamento de Literatura española, Teoría da literatura e Lingüística xeral

Facultade de Filoloxía

Campus Norte - Burgo das Nacións

Universidade de Santiago de Compostela

15782 Santiago de Compostela

Galicia

ESPAÑA

\section{Referencias}

Alonso Montero, X. 2004. Páxinas sobre Rosalía de Castro. Vigo: Edicións Xerais de Galicia.

Anderson, B. 1991. Imagined Communities: Reflections on the Origin and Spread of Nationalism. Revised and extended edition. London: Verso.

Barro, M. T. 1972. As novelas de Rosalía de Castro. - Grial, 37, 328-330.

Blanco, A. 2012. Cultura y conciencia imperial en la España del siglo XIX. Valencia: Universitat de València.

Cabo Aseguinolaza, F. 2011. Exotopía y emergencia. Sobre La hija del mar de Rosalía de Castro. - A. A. Lourenço, O. M. Silvestre, eds., Literatura, espaço, cartografias. Coimbra: Centro de Literatura Portuguesa (Universidade de Coimbra), 17-38.

Cabo Aseguinolaza, F. 2012. El lugar de la literatura española. Volumen 9 de la Historia de la literatura española coordinada por José-Carlos Mainer. Barcelona: Crítica.

Castro, R. de. 1944. Obras completas. Tomo II [V. García Martí, ed.]. Madrid: Aguilar.

Davies, C. 1987. Rosalía de Castro no seu tempo. Vigo: Galaxia.

Davies, C. 1992. La historicidad de la tradición literaria: Galicia, siglo XIX. - Actas do I Congreso Internacional da Cultura Galega. Santiago de Compostela: Xunta de Galicia, 409-413.

Davies, C. 2005. Rosalía de Castro: aislamiento cultural en un contexto colonial. L. Vollendorf, ed., Literatura y feminismo en España (s. XV-XXI). Barcelona: Icaria, $171-186$.

Díaz, N. P. 1972. De Villahermosa a la China [E. Chao Espina, ed.]. Salamanca: Anaya.

Díaz Martín, R. 2000. Estado de la ciencia y la tecnología en la Cuba de 1898: Aportes científicos de cubanos, españoles y extranjeros. - F. Morales Padrón, ed., XIII Coloquio de Historia Canario-Americana; VIII Congreso Internacional de Historia de America (AEA). Las Palmas: Cabildo Insular de Gran Canaria, Departamento de Ediciones, 523-536. [Accesible en http://www.americanistas.es/biblo/textos/08/08-036.pdf]

García Candeira, M. 2012. Más allá de la ansiedad de la autoría: poética del desierto, imaginación femenina y utopía en La hija del mar. - H. González Fernández, M. do C. Rábade Villar, eds., Canon y subversión: la obra narrativa de Rosalía de Castro. Barcelona: Icaria, 99-120. 
Gilbert, S. M., Gubar, S. 1979. The Madwoman in the Attic: The Woman Writer and the Nineteenth-Century Literary Imagination. New Haven: Yale University Press.

Hooper, K. 2006. Novas cartografías nos estudos galegos: Nacionalismo literario, literatura nacional, lecturas posnacionais. - Anuario de Estudos Literarios Galegos 2005, 64-73.

Loureiro, Á. 2003. Spanish Nationalism and the Ghost of Empire. - Journal of Spanish Cultural Studies, 4, 65-76.

Macchi, F., Arroyo Almaraz, A. 2012. La clave americana en el imaginario romántico: Ángel Saavedra, duque de Rivas. - Cuadernos de Ilusración y Romanticismo, 18, 251-262. [Accesible en http://revistas.uca.es/index.php/cir/article/view/1762]

Mainer, J.-C. 2003. La creación de un centro: Madrid, capital del siglo XIX. - Capitales y corte en la historia de España. Valladolid: Universidad de Valladolid, 105-131.

Odriozola, A. 1986. Las ediciones de rosalía de Castro y de su esposo en vida de ambos. - Actas do Congreso Internacional de estudios sobre Rosalía de Castro e o seu tempo. Santiago de Compostela: Consello da Cultura Galega y Universidade de Santiago de Compostela, 93-96.

Otero Pedrayo, R. 1969. El planteamiento decisivo de la novela romántica en Rosalía de Castro. - Cuaderno de Estudios Gallegos, 24, 290-314.

Rábade Villar, M. do C. 2011. Afectos e espazos. Teoría e crítica da cidade na obra narrativa de Rosalía de Castro. - A. A. Lourenço, O. M. Silvestre, eds., Literatura, espaço, cartografias. Coimbra: Centro de Literatura Portuguesa (Universidade de Coimbra), 177-207.

Rábade Villar, M. do C. 2012. Rosalía de Castro y el mito del progreso: elementos para una nueva política del tiempo. - H. González Fernández, M. do C. Rábade Villar, eds., Canon y subversión: la obra narrativa de Rosalía de Castro. Barcelona: Icaria, 99-120.

Rancière, J. 2007. Politique de la littérature. Paris: Galilée.

Rodríguez, F. 1988. Análise sociolóxica da obra de Rosalía de Castro. Vigo: Asociación Socio-Pedagóxica Galega.

Rodríguez, F. 2011. Rosalía de Castro, estranxeira na súa patria (a persoa e a obra de onte a hoxe. Vigo: Asociación Socio-Pedagóxica Galega.

Said, E. 1994. Jane Austen and Empire. Culture and Imperialism. Nueva York: Vintage Books, 80-97.

Tang, C. 2008. The Geographic Imagination of Modernity. Geography, Literature, and Philosophy in German Romanticism. Stanford: Stanford University Press. 